\title{
Learning effect of standard automated perimetry in healthy individuals
}

\author{
Efeito aprendizado da perimetria automática padrão em indivíduos saudáveis
}

\author{
Dinorah Piacentini Engel Castro ${ }^{1}$ \\ Juliana Kawase ${ }^{2}$ \\ Luiz Alberto Soares Melo Jr. ${ }^{3}$
}

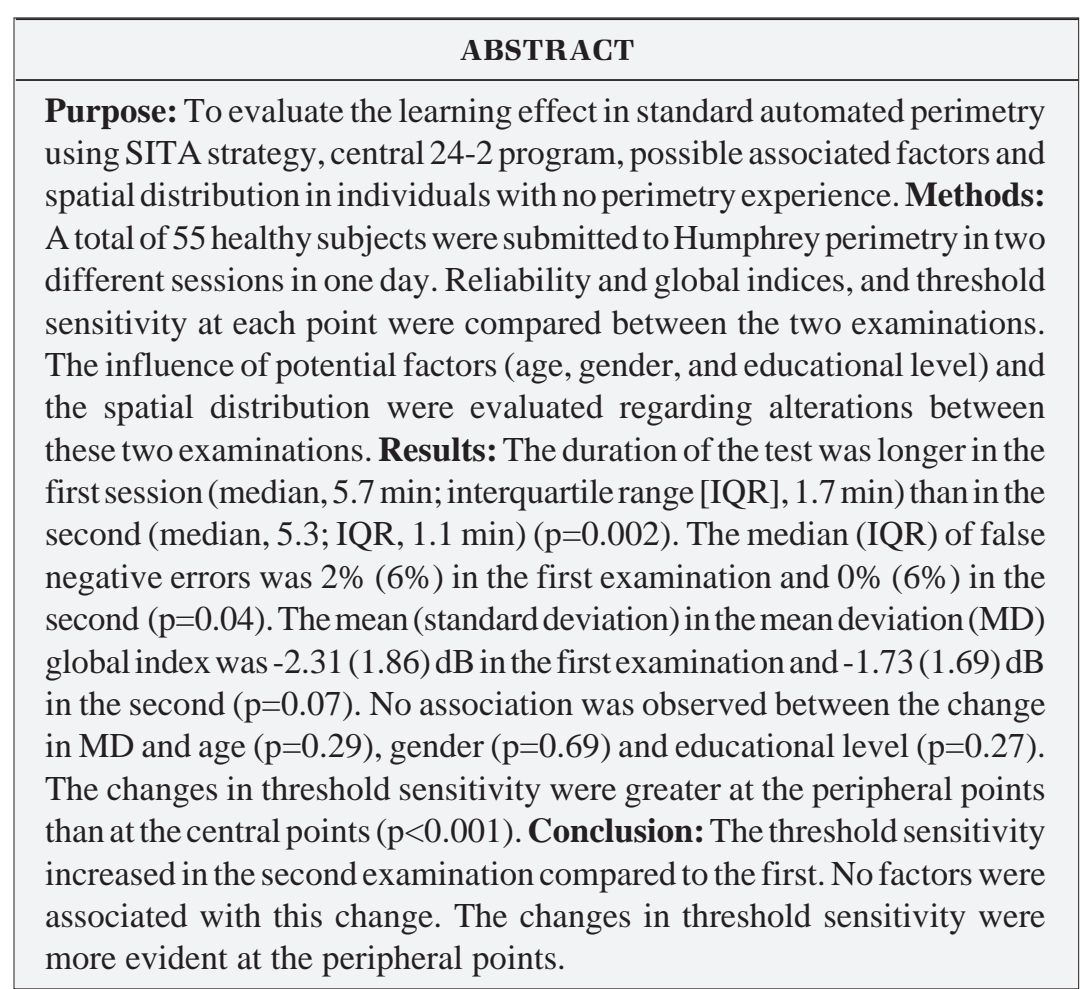

Keywords: Visual fields; Learning; Perimetry; Sensory thresholds; Reference values; Sensitivity and specificity

\section{INTRODUCTION}

Glaucoma is the leading cause of nonreversible blindness and the second cause of all types of blindness in the world ${ }^{(1)}$. It is estimated that over 67 million people in the world are affected and $10 \%$ of those are legally blind $^{(2)}$. Standard automated perimetry (SAP) has been the gold standard for the detection and monitoring of functional loss in glaucoma ${ }^{(3)}$. This examination detects the threshold sensitivity at different locations in the visual field, with good reproducibility, and without examiner influence ${ }^{(4-6)}$.

The learning effect is an important issue in many psychophysical tests. It is generally assumed that the individual experience influences the results of automated perimetry ${ }^{(7)}$. Several studies showed that healthy and glaucomatous individuals can exhibit a learning effect with repeated standard automated perimetry testing ${ }^{(8-16)}$. This effect was also demonstrated in short wavelength automated perimetry ${ }^{(17-18)}$, flicker perimetry ${ }^{(19)}$, and frequency doubling perimetry ${ }^{(20-25)}$. 
Possible factors associated with the learning effect in glaucoma patients have been studied, such as age, race, gender and previous experience ${ }^{(26)}$. However, studies that evaluate the influence of educational level on learning effect of automated perimetry have not been reported, and few studies analyzed the learning effect using Swedish interactive threshold algorithm (SITA) strategy ${ }^{(9-10)}$. The learning effect in perimetry could be influenced by possible associated factors including educational level. The performance of the first perimetry could be improved if a personal approach were provided before and during the examination.

The aim of this study is to evaluate the possible factors, including educational level, associated with learning effect and the spatial distribution of the changes in SAP using SITA strategy performed on the same day in healthy individuals.

\section{METHODS}

This study was approved by the Ethics in Research Committee of the Federal University of São Paulo and conducted according to the tenets of Declaration of Helsinki and Health National Council resolution $\mathrm{n}^{\circ}$ 196/96. Written informed consent was obtained from the participants.

Healthy subjects were recruited from volunteers of the community, institution staff, and spouses or friends of patients. The participants underwent a complete ophthalmic examination including manifest refraction, slit lamp examination, Goldmann applanation tonometry, fundus biomicroscopy using a 78-diopter lens, and binocular indirect ophthalmoscopy. Race was obtained from subjects by self-designation. Educational level was classified according to the school instruction. Individuals with incomplete fundamental education in school were classified as incomplete primary education level. Those who completed fundamental education were classified as complete primary level. The individuals who completed secondary education in school were classified as secondary level. The individuals who completed the university/college were classified as tertiary level.

All recruited participants were 18 years or older, had not previously undergone SAP, had corrected visual acuity better than 20/40, intraocular pressure less than $22 \mathrm{mmHg}$ on two different days, no media opacities except mild cataract (nuclear opalescence and color less than 2, no peripheral cortical cataract, no subcapsular cataract by the Lens Opacities Classification System III ${ }^{(27)}$ ), absence of glaucomatous optic nerve head alterations (optic disc hemorrhages, neuroretinal localized defect, cup disc ratio asymmetry greater than 0,2 ) and retinal nerve fiber layer defects. Exclusion criteria included: pregnancy, previous ocular surgery, retinal diseases, neurological pathologies that could influence the visual field, and incapacitating systemic disease (cerebral vascular disease, senile dementia, severe heart failure).

Detailed instructions about the perimetry, the test characteristics, the test duration, how each individual should perform the examination, were given verbally by either one of the two examiners (D.P.E.C and J.K.) to the participants. SAP (central 24-2 program; SITA strategy- Humphrey-Zeiss Meditec Inc, Dublin, CA, USA) was performed in both eyes of the patients in two different sessions on the same day. The manifest refraction and appropriate addition were corrected with trial lens. In each session, both eyes were examined in a random sequence. During the examination if the examiner noticed lack of attention or misunderstanding of the examination, the test was paused and further explanation was given to the participant. If both eyes were eligible for this study, the first randomly chosen eye was analyzed. The interval between both sessions was 30 minutes or longer. The influence of age, gender and educational level on the learning effect was evaluated.

\section{Statistical analysis}

The statistical analysis was performed using the statistical package Stata 10.0 (StataCorp, College Station, TX, USA). The Wilcoxon signed rank test was used to compare the test duration, fixation loss, false positive and false negative error rates of the SAP between both sessions. The paired $t$ test was performed to compare the foveal sensitivity, mean deviation (MD) and pattern standard deviation (PSD) indices between sessions. The exact symmetry test was used to compare the results of the glaucoma hemifield test (GHT) between sessions.

The within-subject standard deviation (SD) was calculated as the SD of the two threshold levels (one for each session) for each location tested in the SAP. The threshold level of the left eye was inverted for the right eye for analyses (Figure 1). The overall within-subject SD was calculated as the square root of the average within-subject variance of the 52 locations tested in the SAP. Spearman's rank correlation test was used to evaluate the correlation of both the change in MD between sessions and overall within-subject SD with age. Mann-Whitney test was performed to compare both the change in MD between sessions and overall within-subject SD between male and female individuals. A nonparametric test for trend was used to compare the change in MD between sessions and overall within-subject SD between education levels. Friedman test was used to compare the withinsubject SD across the locations tested in the SAP regarding the spatial distribution of the changes. Type I error was set at 0.05 .

\section{RESULTS}

A total of 55 healthy volunteers were enrolled in this study. The mean (SD) age was 44.5 (14.4) years; 24 (44\%) were men and 31 (56\%) women. Regarding race distribution, $2(4 \%)$ individuals were Asian, 31 (56\%) were white, $6(11 \%)$ were black, and 16 (29\%) were mixed. Regarding educational level, $16(29 \%)$ had incomplete primary education, 12 (22\%) had complete primary education, $19(35 \%)$ had secondary education and $8(15 \%)$ had complete tertiary education.

The comparison between the two sessions is shown in the Table. The test duration of the second session (median $5.3 \mathrm{~min}$; lower quartile [Q1] - upper quartile [Q3], 4.7-5.8 min) was sta- 


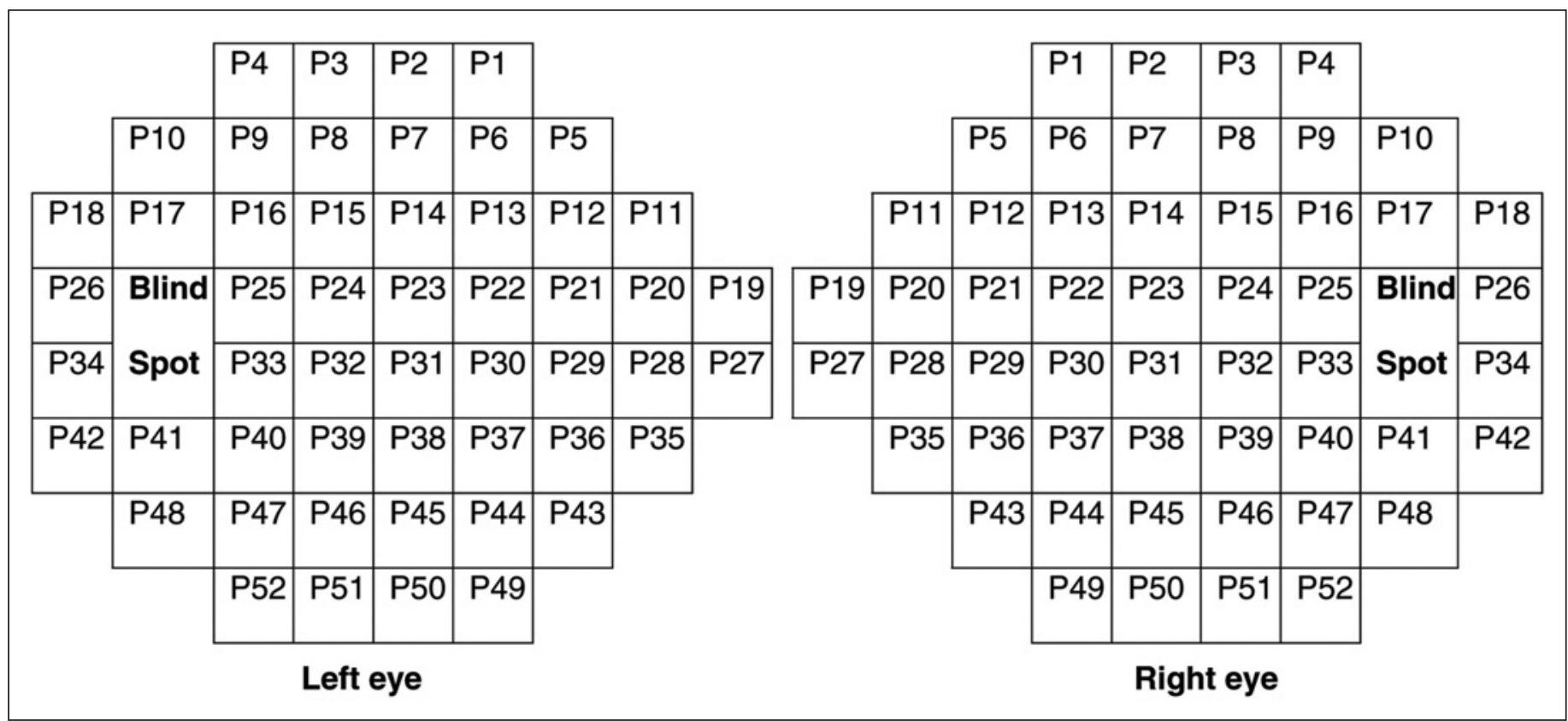

Figure 1 - The distribution of the perimetric points $(p)$ in the left and right eyes that was used in the statistical analysis. The image of the left eye is the mirror image of the right eye.

\begin{tabular}{|c|c|c|c|}
\hline Variable & First session & Second session & $\mathbf{P}$ \\
\hline Test duration, median (Q1 to Q3), min & $5.7(5.1$ to 6.8$)$ & $5.3(4.7$ to 5.8$)$ & 0.002 \\
\hline \multicolumn{4}{|l|}{ Reliability indices } \\
\hline Fixation loss, median (Q1 to Q3),\% & $0 \%(0 \%$ to $13 \%)$ & $6 \%(0 \%$ to $12 \%)$ & 0.490 \\
\hline False positive error, median (Q1 to Q3),\% & $1 \%(0 \%$ to $4 \%)$ & $1 \%(0 \%$ to $3 \%)$ & 0.670 \\
\hline False negative error, median (Q1 to Q3),\% & $2 \%(0 \%$ to $6 \%)$ & $0 \%(0 \%$ to $4 \%)$ & 0.040 \\
\hline Foveal sensitivity, mean (SD), dB & $36.0(2.1)$ & $36.3(2.2)$ & 0.140 \\
\hline \multicolumn{4}{|l|}{ Global indices } \\
\hline $\mathrm{MD}$, mean (SD), dB & $-2.31(1.86)$ & $-1.73(1.69)$ & 0.007 \\
\hline PSD, mean (SD), dB & $2.23(1.40)$ & $1.86(0.90)$ & 0.030 \\
\hline Glaucoma hemifield test, $\mathrm{n}\left(\%^{*}\right)$ & & & 0.770 \\
\hline Within normal limits & $33(60)$ & $38(69)$ & \\
\hline Borderline & $11(20)$ & $8(15)$ & \\
\hline Outside normal limits & $9(16)$ & $7(13)$ & \\
\hline General reduction of sensitivity & $2(4)$ & $1(2)$ & \\
\hline Borderline and general reduction of sensitivity & $0(0)$ & $1(2)$ & \\
\hline
\end{tabular}

tistically significantly lower than that of the first session (median, 5.7 min; Q1- Q3, 5.1-6.8 min) ( $\mathrm{p}=0.002)$. The false negative error in the second session was lower than in the first session $(\mathrm{p}=0.04)$. The mean (SD) MD increased from $-2.31(1.86) \mathrm{dB}$ in the first session to $-1.73(1.69) \mathrm{dB}$ in the second session $(\mathrm{p}=0.007)$. The mean (SD) PSD decreased from 2.23 (1.40) in the first session to $1.86(0.90)$ in the second session $(p=0.03)$. None of the examinations had either positive or false negative errors above $33 \%$. The first session, four examinations (7\%) had fixation loss above $20 \%$; the second session, seven examinations (13\%) had fixation loss above $20 \%$.
No factors were statistically significantly associated with changes in SAP between sessions. The correlation between age and MD change was $0.14(\mathrm{p}=0.29)$, and between age and within subject $\mathrm{SD}$ it was $0.12(\mathrm{p}=0.39)$. The mean (SD) MD change in men was $0.51(0.93) \mathrm{dB}$ and in women was $0.62(1.87) \mathrm{dB}(\mathrm{p}=0.65)$. The mean (SD) within subject SD was $1.66(0.46) \mathrm{dB}$ in men and 2.37 (1.37) $\mathrm{dB}$ in women ( $\mathrm{p}=0.05)$. Regarding the educational level, the mean (SD) difference in MD change between sessions for incomplete primary, complete primary, secondary and tertiary level was, respectively, $0.75(1.76) \mathrm{dB}, 1.06(2.09) \mathrm{dB}, 0.21(0.87) \mathrm{dB}$ and 0.36 (1.20) $\mathrm{dB}(\mathrm{p}=0.27)$. The mean (SD) within subject SD for incomple- 
te primary, complete primary, secondary and tertiary level was, respectively, $2.20(1.25) \mathrm{dB}, 2.36(1.40) \mathrm{dB}, 1.93(1.01) \mathrm{dB}$ and 1.65 $(0.44) \mathrm{dB}(\mathrm{p}=0.16)$.

Greater changes in threshold sensitivity were observed in within subject SD when comparing peripheral points with central points $(\mathrm{p}<0.001)$ (Figure 2$)$.

\section{DISCUSSION}

In this study a learning effect demonstrated by decrease in test duration, false negative errors, PSD, and increase in MD in two SAPs of healthy individuals with no previous perimetric experience, when they performed the exams in the same day was observed. Several studies have reported learning effect both in glaucoma ${ }^{(10,15-16,28)}$ and healthy indivi- duals $^{(7,9,13-14,28-29)}$. Therefore, a change in the threshold sensitivity can be expected between the first two SAP performed by an inexperienced individual.

In this study, none of the factors analyzed was associated with the perimetric changes between the two examinations. Auzen and Work ${ }^{(11)}$ did not find an association between age and learning effect, but they found short fluctuation to increase with age. Kulze et al. did not find association between learning effect and area of the field tested, age, gender, race, previous experience, or parameters on the initial field examination. However, learning effect was positively correlated to defect depth and negatively correlated to fixation losses ${ }^{(26)}$.

To the best of our knowledge no study included educational level as a possible influence factor on the learning effect. Since SAP is a psychophysical test and presents a learning effect, one could think that the higher the educational level, the

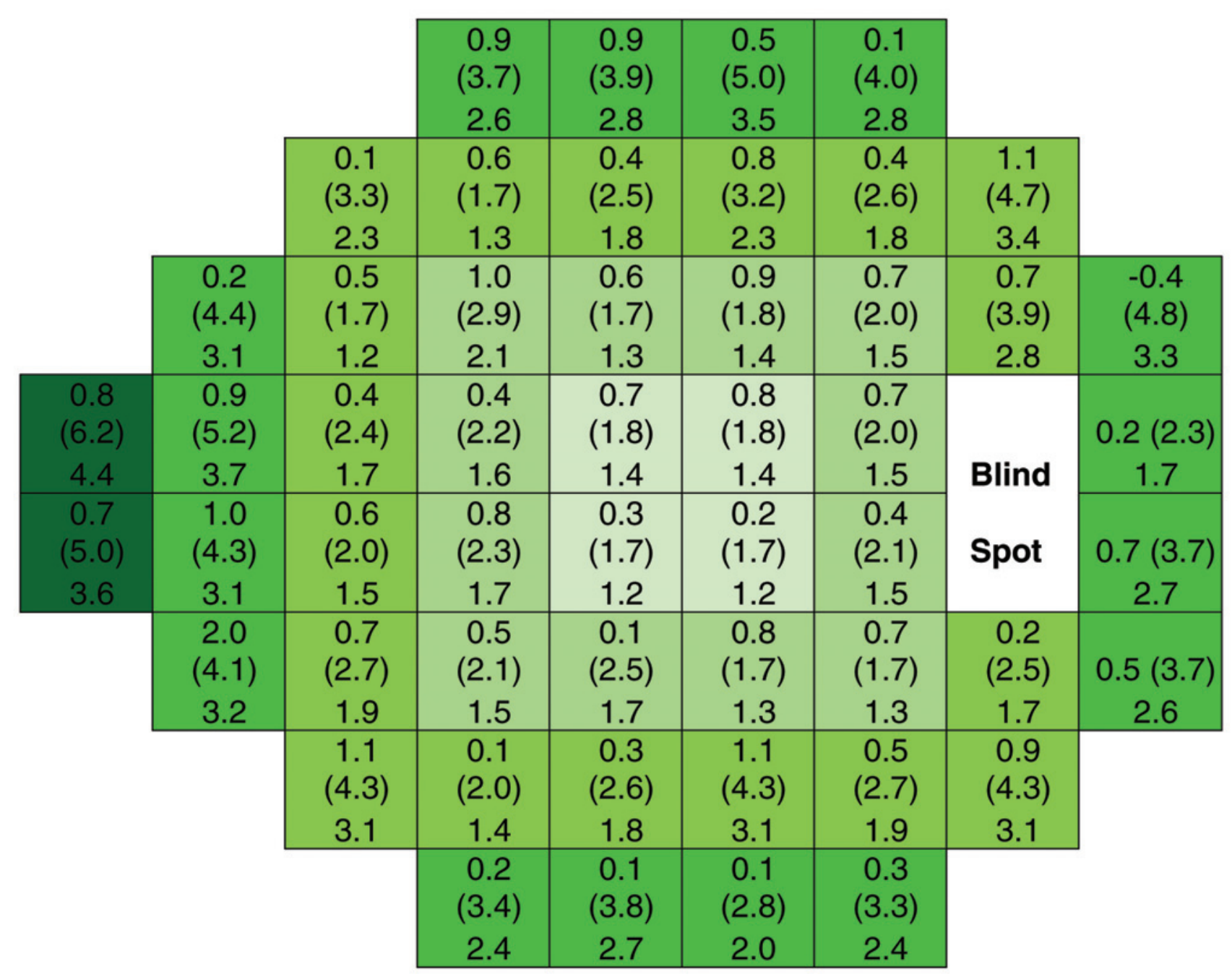

Figure 2 - Spatial distribution of the variation in the threshold sensitivity in the 52 points tested in the standard automated perimetry. The distribution corresponds to the right eye. In each location, the values in the upper part represent the mean (standard deviation) difference (second minus first session) between the two sessions between individuals, and the value in the lower part represents the within-subject standard deviation. The peripheral points are represented by darker green, whereas the central points are represented by lighter green. 
better understanding of the examination, consequently, a better performance could be expected. However, this study did not find association between the educational level and learning effect in SAP. This could be due to the fact that all individuals were given detailed information about the examination before both examinations, and if lack of attention or fixation loss was noted during the testing, the examination was paused and further explanation was given. This routine might have produced a better perimetry result than the situation where the explanation is not given to the patient during the test.

In our study, few examinations had abnormal points. In fact, almost all examinations were within normal limits and the first examination was reliable. This could explain why we found little improvement between the two examinations.

In our study, all individuals had no previous experience with any type of perimetry. One study indicated that patients with previous manual perimetric experience failed to show a learning effect, while patients who had never undergone prior visual field testing improved on a second examination ${ }^{(12)}$. One report showed that in glaucoma patients who had previous manual perimetry experience, only the short-term fluctuation index improved while the average mean defect failed to chan$\mathrm{ge}^{(30)}$. Another study did not find association between previous experience and learning effect ${ }^{(26)}$.

In this study, greater changes in threshold sensitivity were also observed at peripheral than at the central test point locations. Heijl et al. ${ }^{(7)}$, and Wood et al. ${ }^{(13)}$, also found that the learning effects were stronger in the periphery in agreement with our results.

One possible limitation of this study is that only two examinations were performed to analyze the learning effect. However, if further examinations were done in the same day, patients could have fatigued. Moreover, Heijl et al. showed that most improvement in SAP occurs in the first few tests ${ }^{(7)}$. It is important to note that both eyes of the individual were examined in each session. Despite the fact that only one eye was included in the analysis. Therefore, the second examination included in the analysis of this study was, actually, the third experience of the individual with SAP.

\section{CONCLUSION}

There was an increase in threshold sensitivity between the first and the second examination sessions. No factors were associated with this increase. The changes in threshold sensitivity between examinations were more evident in the peripheral than in central locations in SAP. Therefore, normal patients independent of age, gender, or instruction level, should perform at least two perimetries. Even the individuals with high level of instruction still present learning effect.

\section{RESUMO}

Objetivo: Avaliar o efeito aprendizado da perimetria automatizada padrão com a estratégia SITA, programa central 24-2, possíveis fatores associados e distribuição espacial em indivíduos inexperientes em perimetria. Métodos: Um total de 55 indivíduos saudáveis foi submetido a exame de perimetria com aparelho Humphrey em duas sessões no mesmo dia. Foram comparados os índices de confiabilidade, globais e limiares de sensibilidade de cada ponto entre os exames. Foram analisados potenciais fatores relacionados (idade, sexo e nível educacional), bem como a distribuição espacial em relação à alteração entre os exames. Resultados: A duração do exame foi maior na primeira sessão (mediana, 5,7 min; amplitude interquartil [AIQ], 1,7 min) do que na segunda (mediana, 5,3; AIQ, $1,1 \mathrm{~min})(\mathrm{p}=0,002)$. A mediana (AIQ) da taxa de falsos negativos foi $2 \%(6 \%)$ no primeiro exame e $0 \%(4 \%)$ no segundo exame $(\mathrm{p}=0,04)$. A média (desvio padrão) do índice global desvio médio (MD) foi -2,31 $(1,86) \mathrm{dB}$ no primeiro exame e $-1,73$ $(1,69) \mathrm{dB}$ no segundo exame ( $\mathrm{p}=0,007)$. Não houve associação entre a mudança do $\mathrm{MD}$ em relação à idade $(\mathrm{p}=0,29)$, sexo $(\mathrm{p}=0,69)$ e nível de escolaridade $(\mathrm{p}=0,27)$. Houve maior alteração na sensibilidade dos pontos periféricos em relação aos pontos centrais $(\mathrm{p}<0,001)$.Conclusão: Houve melhora dos limiares de sensibilidade entre o primeiro e segundo exames. Não foram detectados fatores associados a estas mudanças. Nos pontos mais periféricos do exame, tais mudanças foram mais acentuadas.

Descritores: Campos visuais; Perimetria; Aprendizagem; Limiar sensorial; Valores de referência; Sensibilidade e especificidade

\section{REFERENCES}

1. Congdon N, O’Colmain B, Klaver CC, Klein R, Muñoz B, Friedman DS, et al. Causes and prevalence of visual impairment among adults in the United States. Arch Ophthalmol. 2004;122(4):477-85.

2. Quigley HA, Broman AT. Number of people with glaucoma worldwide in 2010 and 2020. Br J Ophthalmol. 2006;90(3):262-7. Comment in: Br J Ophthalmol. 2006;90(3):253-4.

3. Fankhauser F, Koch P, Roulier A. On automation of perimetry. Albrecht Von Graefes Graefes Arch Clin Exp Ophthalmol. 1972;184(2):126-50.

4. Anderson DR, Patella VM. Automated static perimetry. $2^{\text {nd }}$ ed. St Louis: Mosby Year Book; 1999.

5. Shirato S, Inoue R, Fukushima K, Suzuki Y. Clinical evaluation of SITA: a new family of perimetric testing strategies. Graefes Arch Clin Exp Ophthalmol. 1999;237(1):29-34.

6. Bengtsson B, Heijl A. Evaluation of a new perimetric threshold strategy, SITA, in patients with manifest and suspect glaucoma. Acta Ophthalmol Scand. 1998;76(3):268-72.

7. Heijl A, Lindgren G, Olsson J. The effect of perimetric experience in normal subjects. Arch Ophthalmol. 1989;107(1):81-6.

8. Werner EB, Krupin T, Adelson A, Feitl ME. Effect of patient experience on the results of automated perimetry in glaucoma suspect patients. Ophthalmology. 1990;97(1):44-8.

9. Schimiti RB, Avelino RR, Kara-José N, Costa VP. Full-threshold versus Swedish Interactive Threshold Algorithm (SITA) in normal individuals undergoing automated perimetry for the first time. Ophthalmology. 2002;109(11): 2084-92; discussion 2092.

10. Schimiti RB, Arciery ES, Avelino RR, Matsuo T, Costa VP. Full-threshold vs. Swedish Interactive Threshold Algorithm (SITA) em pacientes glaucomatosos submetidos à perimetria computadorizada pela primeira vez. Arq Bras Oftalmol. 2006;69(2):145-50.

11. Autzen T, Work K. The effect of learning and age on short-term fluctuation and mean sensitivity of automated static perimetry. Acta Ophthalmol (Copenh) 1990;68(3):327-30.

12. Kosoko O, Sommer A, Auer C. Duration of automated suprathreshold vs 
quantitative threshold field examination. Impact of age and ocular status. Arch Ophthalmol. 1986;104(3):398-401.

13. Wood JM, Wild JM, Hussey MK, Crews SJ. Serial examination of the normal visual field using Octopus automated projection perimetry. Evidence for a learning effect. Acta Ophthalmol (Copenh). 1987;65(3):326-33.

14. Flammer J, Drance SM, Zulauf M. Differential light threshold. Short and long term fluctuation in patients with glaucoma, normal controls, and patients with suspected glaucoma. Arch Ophthalmol. 1984;102(5):704-6.

15. Heijl A, Bengtsson B. The effect of perimetric experience in patients with glaucoma. Arch Ophthalmol. 1996;114(1):19-22.

16. Nordmann JP, Brion F, Hamard P, Mouton-Chopin D. [Evaluation of the Humphrey perimetry programs SITA Standard and SITA Fast in normal probands and patients with glaucoma]. J Fr Ophthalmol. 1998;21(8):549-54.

17. Wild JM, Moss ID. Baseline alterations in blue-on-yellow normal perimetric sensitivity. Graefes Arch Clin Exp Ophthalmol. 1996;234(3)141-9.

18. Rosseti L, Fogagnolo P, Miglior S, Centofanti M, Vetrugno M, Orzalesi N. Learning effect of short-wavelength automated perimetry in patients with ocular hypertension. J Glaucoma. 2006;15(5):399-404.

19. Bernardi L, Costa VP, Shiroma LO. Flicker perimetry in healthy subjects: influence of age and gender, learning effect and short term fluctuation. Arq Bras Oftalmol. 2007;70(1):91-9.

20. Matsuo H, Tomita G, Suzuki Y, Araie M. Learning effect and measurement variability in frequency-doubling technology perimetry in chronic open-angle glaucoma. J Glaucoma. 2002;11(6):467-73.

21. Fujimoto N, Minowa K, Miyauchi O, Hanawa T, Adachi-Usami E. Learning effect for frequency doubling perimetry in patients with glaucoma. Am J Ophthalmol. 2002;133(2):269-70.
22. Horani A, Frenkel S, Yahalom C, Farber MD, Ticho U, Blumenthal EZ. The learning effect in visual field testing of healthy subjects using frequency doubling technology. J Glaucoma. 2002;11(6):511-6.

23. Iester M, Capris P, Pandolfo A, Zingirian M, Traverso CE. Learning effect, short-term fluctuation, and long-term fluctuation in frequency doubling technique. Am J Ophthalmol. 2000;130(2):160-4.

24. Pierre-Filho PT, Schimiti RB, Vasconcellos JP, Costa VP. Sensitivity and specificity of frequency-doubling technology, tendency-oriented perimetry, SITA Standard and SITA Fast perimetry in perimetrically inexperience individuals. Acta Ophthalmol Scand. 2006;84(3):345-50.

25. Hong S, Na K, Kim CY, Seong GJ. Learning effect of Humphrey Matrix perimetry. Can J Ophthalmol. 2007;42(5):707-11.

26. Kulze JC, Stewart WC, Sutherland SE. Factors associated with a learning effect in glaucoma patients using automated perimetry. Acta Ophthalmol (Copenh). 1990;68(6):681-6.

27. Chylack LT Jr, Wolfe JK, Singer DM, Leske MC, Bullimore MA, Bailey IL,et al. The Lens Opacities Classification System III. The Longitudinal Study of Cataract Group. Arch Ophthalmol. 1993;111(6):831-6.

28. Salvetat ML, Zeppieri M, Parisi L, Brusini P. Rarebit perimetry in normal subjects: test-retest variability, learning effect, normative range, influence of optical defocus, and cataract extraction. Invest Ophthalmol Vis Sci. 2007; 48(11):5320-31.

29. Stewart WC, Hunt HH. Threshold variation in automated perimetry. Surv Ophthalmol. 1993;37(5):353-61.

30. Werner EB, Adelson A, Krupin T. Effect of patient experience on the results of automated perimetry in clinically stable glaucoma patients. Ophthalmology. 1988;95(6):764-7. 